\title{
Eine einfache Idee und eine App, um Leben zu retten
}

\section{Jocelyn Corniche}

Oberarzt Anästhesie und Notaufnahme, CHUV Lausanne

Am Anfang meiner Idee steht eine lange Dienstnacht, in der ich mich um einen jungen Mann kümmere, der eine Woche zuvor bei einem Verkehrsunfall ein schweres Schädel-Hirn-Trauma erlitten hat. Die Ereignisse überschlagen sich, und der Patient muss für klinisch tot erklärt werden. Trauernd an seiner Seite die Familie und Eltern. Ihnen steht noch ein schwerer Moment bevor, denn sie müssen die Frage beantworten, ob ihr Sohn Organspender ist. Aber darauf haben sie keine Antwort, weil sie das Thema nie angesprochen haben: Ihr Sohn war schliesslich jung und gesund. Wir suchen in seinen Sachen nach einer Organspendekarte, finden aber keine. Die Entscheidung fällt der Familie sehr schwer, und schliesslich beschliesst sie, nichts zu unternehmen: Ihr Sohn wird seine Organe nicht spenden. Das ist ein grosses Problem in der Schweiz: Ist der Wunsch eines Patienten nicht bekannt, wendet sich das medizinische Personal in der Regel an die Familie. Und meistens lehnt sie ab, da der Moment, in dem man vom Tod eines geliebten Menschen erfährt, der denkbar ungünstigste Zeitpunkt für eine so schwerwiegende Entscheidung ist.

Ich verlasse das Spital, müde und frustriert, und gehe nach Hause, um mich ein wenig zu erholen. Einige Stunden später wache ich auf und habe das Bedürfnis nach Ablenkung. Ich beschliesse, ein wenig zu shoppen und gehe in ein grosses schwedisches Möbelhaus in der Nähe. An der Kasse angekommen, lege ich die Treuekarte vor, die auf meinem Smartphone als App installiert ist, und bezahle. Abends wollen Freunde zu Besuch kommen, ich muss noch einige Einkäufe erledigen. Wieder zeige ich beim Bezahlen meine

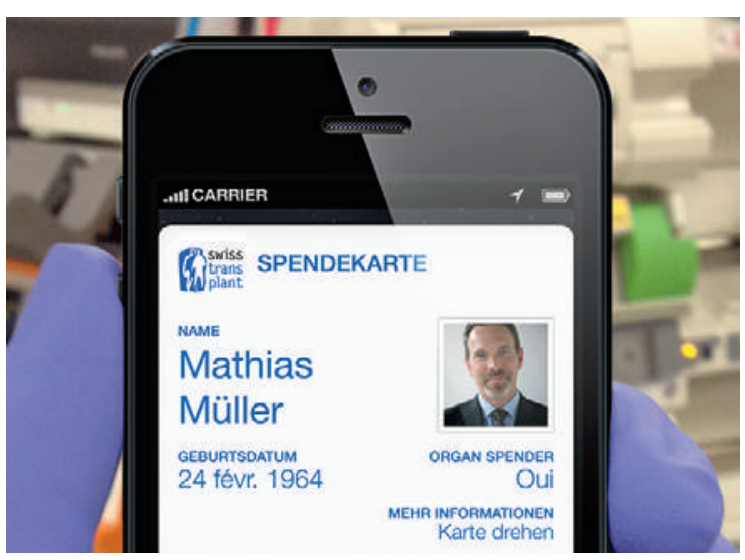

Kundenkarte auf dem Smartphone. Zu Hause angekommen, lasse ich die Ereignisse im Krankenhaus Revue passieren und eine Idee beginnt zu wachsen ... Einen Monat später ist alles zu Papier gebracht. Ich will eine digitale Organspendekarte entwickeln, die man auf dem Smartphone installieren kann. Ich stelle mein Projekt dem Vorsitzenden der Stiftung Swisstransplant vor, die meine Idee unterstützt. Wenige Wochen später verfüge ich bereits über einen funktionierenden Prototyp. Stolz führe ich ihn einem Freund vor. Der sagt: «Super, tolle Idee, aber wie kann man auf die Karte zugreifen, wenn das Telefon gesperrt ist?» Da wird mir auf einmal klar, dass mein ganzes Projekt in sich zusammenbricht: Meine Spendekarte ist für das Spital unzugänglich, da die meisten Telefone mit einem Code gesperrt sind.

Installieren Sie Ihre elektronische Swisstransplant-Organspendekarte mit dem App Echo112 oder besuchen Sie www.emergencyID.ch

In der folgenden Nacht erinnere ich mich an einen Artikel über eine neue Technologie: Bluetooth-Tags, über die man sogar mit gesperrten Smartphones interagieren kann. Ich beschaffe mir ein Exemplar und stelle mit Begeisterung fest, dass es bestens funktioniert! Die Organspendekarte erscheint automatisch auf dem eigentlich gesperrten Bildschirm, wenn das Telefon das Tag ausfindig macht. Die Lösung! Nun gilt es nur noch, die Krankenhäuser davon zu überzeugen, ihre Notaufnahmen mit diesen Tags auszustatten. Das dauert länger als gehofft, da es sich um eine weitgehend noch unbekannte Technologie handelt. Aber mit etwas Ausdauer und einigen Erklärungen erkennen die meisten Krankenhäuser das Potential und sind einverstanden, ihre Notaufnahmen mit diesen Tags auszustatten. Derzeit, also nur zwei Monate nach Einführung der elektronischen Organspendekarte, haben bereits 50000 Schweizerinnen und Schweizer sie heruntergeladen Tendenz steigend. Mit einer einfachen Idee, einer App und ein paar Menschen, die an das Projekt glauben, lässt sich manchmal wirklich etwas verändern.

Um Ihr Spital auszustatten oder kostenlose Unterlagen für Ihre Patienten anzufordern, schreiben Sie bitte an info[at]emergencyid.ch 